\title{
INTRAEMPREENDEDORISMO NO SERVIÇO PÚBLICO: UM ESTUDO DA VIABILIDADE A PARTIR DA GESTÃO INOVADORA
}

\author{
INTRAEMPREENDEDORISM IN THE PUBLIC SERVICE: A STUDY OF VIABILITY FROM \\ INNOVATIVE MANAGEMEN
}

\author{
Recebido em 21.02.2019 Aprovado em 10.12.2019 \\ Avaliado pelo sistema double blind review \\ DOI: https://doi.org/10.32888/cge.v7i2.28127
}

\author{
Maria Aparecida Teles da Rocha \\ aparecidateles17@gmail.com \\ Curso de Administração/Universidade Federal do Piauí - UFPI/Floriano/Piauí, Brasil
}

Jairo de Carvalho Guimarães

jairoguimaraes@ufpi.edu.br

Curso de Administração/Universidade Federal do Piauí - UFPI/Floriano/Piauí, Brasil

\section{Resumo}

As crescentes transformações têm demandado dos profissionais, tanto do meio empresarial quanto de instituições públicas, posturas proativas e decisões imediatas, tendo em vista que as dificuldades em tomar rápidas decisões são complexas em empresas públicas, pela submissão à legislação. Em ambientes de estruturas estáticas submetidos ao controle orçamentário, empreender torna-se um desafio. Porém, há indivíduos que em espaços pouco convidativos à inovação conseguem revolucionar, extraindo de situações adversas resultados inesperados. São chamados intraempreendedores, os quais não se conformam em fazer apenas o convencional e, diante de um problema, buscam soluções diferenciadas. Esta pesquisa abordou três gestores de Instituições Federais de Ensino (IFE) visando a desvelar se é possível a iniciativa empreendedora neste ambiente. A pesquisa é qualitativa, de natureza descritiva-exploratória, utilizando-se da Análise de Conteúdo para interpretar os depoimentos sob a técnica do Estudo de Caso. Comprovou-se que os gestores desenvolvem ações empreendedoras, mesmo considerando a rigidez para o manejo gerencial, característica típica em organizações públicas sob o signo do sistema burocrático.

Palavras-chave: Serviço Público. Intraempreendedorismo. Gestão. Inovação.

\begin{abstract}
The growing transformations have demanded from the professionals, both from the business community and from public institutions, proactive positions and immediate decisions, considering that the difficulties in taking fast decisions are complex in public companies, by the submission to the legislation. In environments of static structures subject to budgetary control, undertaking becomes a challenge. However, there are individuals who in spaces that are not inviting to innovation can revolutionize, extracting from unexpected situations unexpected results. They are called intrapreneurs, who are not content to do only the conventional and, in the face of a problem, seek differentiated solutions. This research addressed three managers of Federal Education Institutions (IFE) in order to unveil if it is possible the entrepreneurial initiative in this environment. The research is qualitative, of a descriptive-exploratory nature, using the Content Analysis to interpret the statements under the technique of the Case Study. It has been proven that managers develop entrepreneurial actions, even considering the rigidity for managerial dexterity, a typical feature in public organizations under the sign of the bureaucratic system.
\end{abstract}

Keywords: Public Service. Intrapreneurship. Management. Innovation. 


\section{Introdução}

Para viver em sociedade o homem desenvolveu regras para seu funcionamento harmônico, passando o ser humano ao longo de sua vida ter contato com diversas organizações, desde as mais simples em seu primeiro estágio de vida, como a família, até as mais complexas que permitem geração de renda e funcionamento produtivo, como as empresas. Assim, para melhor reger a vida social, criou-se o Estado que, segundo Dalari (2012), é uma situação permanente de convivência ligada à sociedade política. $\mathrm{O}$ Estado passou assim a ser responsável pelo atendimento do bem comum, para tanto, instituições públicas foram criadas, e o funcionamento de tais instituições é regido pela Administração Pública, esta, essencialmente burocrática.

Desse modo, na busca pelos objetivos de forma eficiente, o caráter legalista da ação gerencial tornase, muitas vezes, impedida. A fim de não se desviar dos seus objetivos, no entanto, adicionada à recomendação em atender literalmente as regras impostas, consigna ao sistema público um exemplo fechado e pouco convidativo à inovação. Neste ambiente de estruturas estáticas - Serviço Público muitas pessoas desenvolvem seus trabalhos e algumas delas seguem à risca os protocolos ao desempenhar as suas funções, porém, outros profissionais, não obstante comporem uma instituição subjacente ao modelo burocrático, desempenham tarefas de forma criativa, ágil, assertiva e flexível de modo que conseguem dominar situações adversas extraindo o melhor possível. Estes são os que se pode denominar de intraempreendedores. São indivíduos que, mesmo em um sistema reputado fechado, face às peculiaridades do modelo imposto, desenvolvem mecanismos alternativos de ideação, solução e decisão.

A partir de um cenário socioeconômico e político complexo, o qual não permite assegurar um encaminhamento seguro para o futuro da sociedade brasileira, questão esta adstrita à condução de comportamentos politicamente incorretos, há de se perguntar de que forma se deve buscar a solução para os problemas graves que vive a sociedade moderna em toda a sua contextualização. Tomando esta análise como ponto de referência, pode-se aferir que uma saída factível está assentada na iniciativa de algumas pessoas que, insatisfeitas pela situação atual e desejosas por modernismos necessários à plena atuação estatal, trabalham em busca de alternativas que possam contribuir para a sua evolução, pessoal e profissional.

Assim, mesmo observando o ambiente público, o qual sugere se constituir em espaço de baixa eficiência e pouco afeito à rapidez - fator essencial às organizações privadas sob um espectro de forte competitivdade - e com um corpo de servidores geralmente desmotivados, há condições para que as pessoas possam empreender, tornando o espaço um celeiro de criação, inovação e transformação. Diante do exposto, a proposta deste estudo abrange as estruturas burocráticas e funcionais das organizações públicas e busca identificar como os gestores exercem seu papel dentro das mesmas, cujo lócus são as Instituições Federais de Ensino (IFE) e como a gestores das mesmas buscam inovar dentro das estruturas. Sob este aspecto, lançou-se a seguinte questão: É possível ser empreendedor dirigindo uma Instituição Federal de Ensino? O objetivo do estudo é descrever a possibilidade de empreender na gestão de uma Instituição Federal de Ensino.

O mundo do trabalho mudou e as recentes transformações que têm ocorrido no universo do trabalho e da gestão indicam a necessidade de que novos modelos de direção e gerenciamento sejam estabelecidos como forma de adequar a organização às demandas de uma sociedade cada vez mais ávida por novos produtos, processos, serviços e maneiras ágeis de soluções de suas demandas. A eficiência, neste ponto, é elemento indissociável na busca pela atuação efetiva do Serviço Público (PEREIRA; SILVA, 2011). Com efeito, avaliando que as pessoas passaram a ter um maior domínio dos seus direitos, exigindo suporte e resposta imediatos às necessidades e com fundamento no 
construto da cidadania, as empresas públicas de forma geral têm sido alvo de cobranças para que os serviços respondam satisfatoriamente àquelas demandas. Mais: que as soluções venham de maneira tempestiva e plena. Sob esta ótica, é fundamental que os órgãos públicos desenvolvam ações e procedimentos capazes de entregar adequada e no tempo devido as demandas de uma sociedade ainda injustiçada pelo desequilíbrio na distribuição das riquezas do país.

Assim, buscam-se nas organizações públicas práticas que justifiquem os investimentos, sempre oriundos na aplicação de tributos, extensivos a todo o conjunto da sociedade. A proposta deste trabalho é possibilitar compreender que, mesmo atuando em instituições que têm limitações orçamentárias e estruturais, face ao contingenciamento de recursos e da estrita observância aos Princípios da Legalidade, da Impessoalidade, da Eficiência, da Publicidade e da Moralidade, notadamente em um cenário de forte recessão e baixo emprego - que, ao cabo, reduz a arrecadação do ente estatal - o estilo empreendedor pode ser implementado. Para conceder fundamento ao trabalho, é imprescindível o conhecimento de alguns conceitos, os quais auxiliarão no entendimento da concepção de intraempreendedorismo aplicado na gestão pública e suas contribuições no manejo gerencial.

\section{Empreendedorismo}

Empreender, palavra que descreve uma ação em alta no Brasil, com a crise tudo se resume a criar seu próprio negócio, inovar e fazer a diferença no mercado. Todavia, o empreendedorismo não está apenas restrito a negócios e empresas privadas, sob a aura econômica. Ao contrário desta concepção, vai além e alcança outras vertentes, como o empreendedorismo social e o organizacional. Etimologicamente falando, a palavra empreendedorismo decorre do francês, "entre" e "prendre" que significa qualquer coisa, como "estar no mercado entre o fornecedor e o consumidor" (SARKAR, 2008, p. 21).

De modo geral os conceitos envolvem ideias, pessoas e transformação e, desse modo, o empreendedor pode ser definido como alguém visionário que se utiliza de novas ideias e as introduz em um mercado transformando vidas e realidades, tendo como base o inconformismo. "Empreendedorismo significa fazer algo novo, diferente, mudar a situação atual e buscar, de forma incessante, novas oportunidades de negócios, tendo como foco a inovação e a criação de valor", assevera Dornelas (2008, p. 35). Nos conceitos apresentados é possível visualizar elementos dados como essenciais na atividade empreendedora: a inovação ao se criar atuação em novos mercados e/ou área; o risco da atividade por ser nova e incerta e a autonomia que se traduz na atitude inconformada e iniciativa de mudar a realidade. No Quadro 1 é possível identificar alguns elementos que constituem o comportamento empreendedor.

\section{Quadro 1 - Elementos do Empreendedorismo}

\begin{tabular}{|c|l|}
\hline ELEMENTO & DESCRIÇÃO \\
\hline Inovação & $\begin{array}{l}\text { O papel do empreendedor não se limita à criação de negócios ele compreende também a criação } \\
\text { de um método de produção, a abertura de um novo mercado, a busca por alternativas de materiais } \\
\text { e a promoção de mudanças de mudanças estruturais na organização. }\end{array}$ \\
\hline Risco & $\begin{array}{l}\text { Nenhum empreendimento está livre de riscos, quanto maior a incerteza maior a imprevisibilidade } \\
\text { dos resultados, o risco é composto por três fatores básicos: as anomalias ou variações aos quais os } \\
\text { produtos, processos e serviços estão sujeitos; probabilidade de ocorrências de tais anomalias e a } \\
\text { gravidade das consequências dessas ocorrências; a probabilidade de não conseguir vender e as } \\
\text { decorrências geradas por não vender. }\end{array}$ \\
\hline Autonomia & $\begin{array}{l}\text { O empreendedor goza de autonomia para definir os objetivos, decidir sobre o uso de recursos, } \\
\text { escolher as estratégias de ação e até mesmo para buscar oportunidades relevantes. }\end{array}$ \\
\hline
\end{tabular}

Fonte: Hashimoto, 2006, p. 4-5. 
Inovação, risco e autonomia! Estes três elementos mostram-se indispensáveis na criação de novos produtos, processos e exploração de novos mercados, em uma organização a ser criada ou existente. A inovação decorre de oportunidades criadas ou em muitos casos detectada, o empreendedor capta a oportunidade, assume os riscos e decide por meio da autonomia como agir e se deve agir naquilo que acredita. No entanto, os riscos que se propõe a correr geram uma certa incerteza que pode resultar em inibição da ação empreendedora. Para Hisrich, Peters e Shepherd (2014, p. 6), empreendedores precisam avaliar o "[...] o nível de incerteza percebido em torno de uma oportunidade em potencial e a disposição do indivíduo de enfrentar essa certeza". O modelo McMullen-Shepherd é utilizado para explicar e classificar o impacto que o conhecimento e a motivação produzem no ato da ação empreendedora.

Figura 1 - A Conceptual Model Relating Perceived Uncertainty and Motivation to Entrepreneurial Action

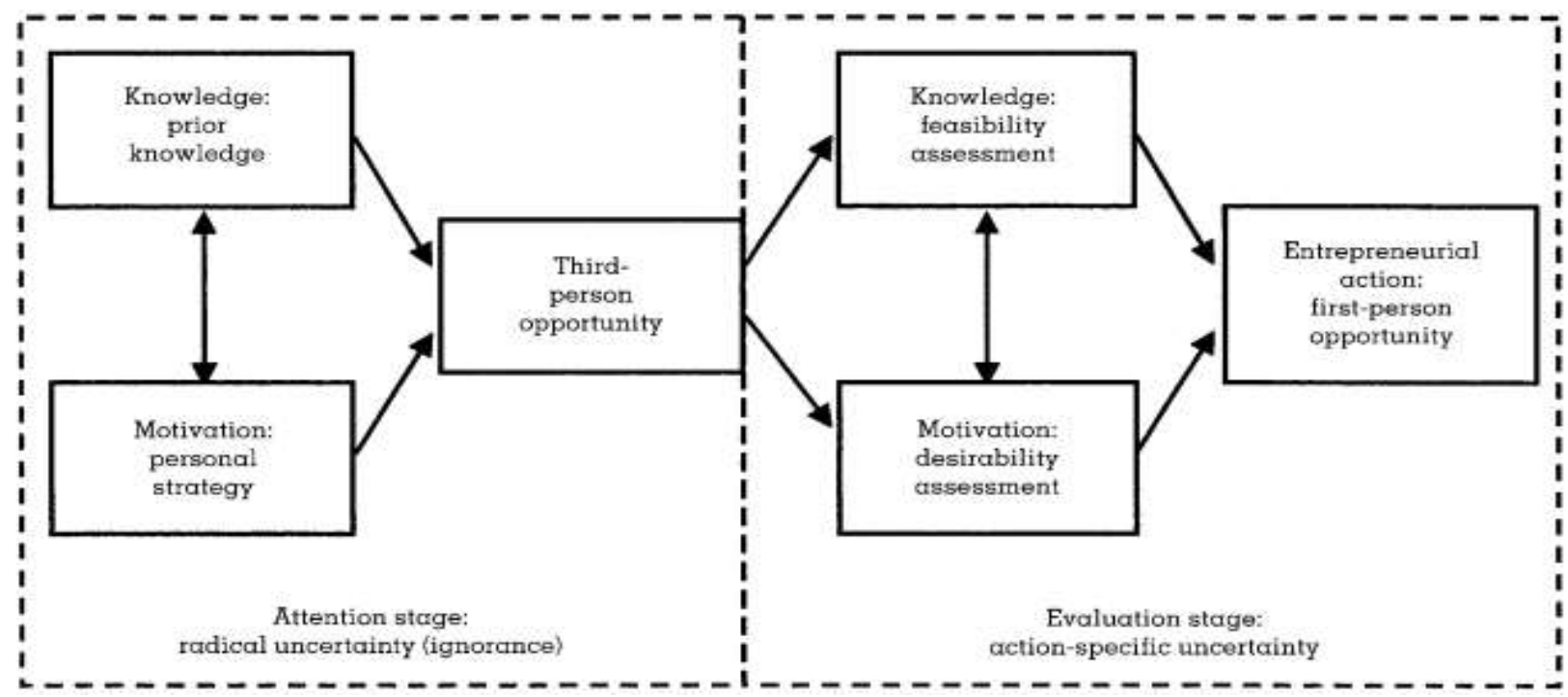

Fonte: McMullen-Shepherd, 2006, p. 132.

No modelo estruturado na Figura 1 são descritos os estágios da ação empreendedora. No primeiro estágio é possível observar que o conhecimento prévio gera a motivação e consequentemente a motivação é apresentada como fator-chave de geração de conhecimento, ou seja, a motivação leva o indivíduo a desejar e buscar capacitar-se e isso leva à classificação da motivação como uma estratégia pessoal. Os dois exercícios contribuem para a identificação de oportunidades, essa perceptível por alguns indivíduos. O estágio 1 é assim entendido como o grau de sensibilidade e percepção que o indivíduo tem sobre as oportunidades. $\mathrm{O}$ estágio 2 leva o indivíduo à análise da oportunidade no tocante à viabilidade e, neste estágio, aspectos como níveis de atratividade têm um peso significativo na tomada de decisão. Assim, a motivação está direcionada à avaliação de predisposição e o conhecimento à avaliação de viabilidade, desse modo, a ação empreendedora só se torna efetiva depois do aprofundado estudo da oportunidade, e se tal oportunidade é favorável ao investimento, ou seja, se há viabilidade para a execução da proposta idealizada.

Portanto, a ação empreendedora se efetiva depois do estudo da motivação inicial, assim como da análise da viabilidade. Esta condição desmistifica a lenda do empreendedor despreparado, visto que é necessário ir além da motivação, havendo uma gama de conhecimentos para iniciar-se um processo empreendedor. Neste sentido, a atitude empreendedora no âmbito de Instituições de Federais Ensino está assentada na formação do processo motivacional e na necessidade de conhecimento prévio, que 
aqui está designado pela percepção acerca do funcionamento da unidade educacional e das demandas que são geradas pelo conjunto dos indivíduos que dela participam e por ela são atendidos. $O$ comportamento empreendedor pode estar presente nos indivíduos que executam as mais variadas funções, por assim dizer.

Em suma, o comportamento empreendedor diz respeito aos indivíduos visionários, questionadores, inconformados, ousados, que desejam fazer diferente, que enfrentam os desafios. Possuem uma postura inconformista e revolucionária, visto que são reconhecidos como pessoas criativas e inovativas por natureza, desenvolvendo em qualquer esfera da sociedade medidas de forma a quebrar estruturas estáticas, buscando dinamizar processos e performances. Pode-se afirmar que a iniciativa empreendedora no ambiente organizacional - intraempreendedorismo - está assentada no viés comportamental do sujeito, não obstante, neste espaço de ação, haver reconhecidas restrições para o desenvolvimento de procedimentos inovativos, criativos e transformadores.

\section{Intraempreendedorismo e Criatividade}

Muito se tem debatido sobre empreendedorismo e como ele pode estimular as pessoas, razão pela qual o termo intraempreendedorismo tem ganhado cada vez mais espaço. Como conceito, define "aquele que dentro da organização assume a responsabilidade de promover a inovação de qualquer tipo, a qualquer momento e em qualquer lugar da empresa" (HASHIMOTO, 2006, p. 21). Autores apontam o intraempreendedor como alguém que inova, cria oportunidades, promove novas combinações (WUNDERER, 2001), muda o centro nervoso da atividade e renova as estratégias (ZAHRA, 1996) e promove processos inovativos, realizando transformações nos modelos mentais por meio das competências (PEREIRA; SILVA, 2011).

O intraempreendedor é a pessoa que, protegido em uma organização, propõe-se a quebrar paradigmas ao tecer novas formas de desenvolver tarefas e funções de maneira inovadora. Para Luchsinger e Bagby (1987), a personalidade intraempreendedora expressa algumas características, como o questionamento do status quo, é um indivíduo motivado pela resolução de problemas, mudanças e inovação, sente frustração pelos sistemas burocráticos, são ambiciosos, competitivos, corajosos e autoconfiantes e têm necessidade de realização. No entanto, agir de forma empreendedora dentro de uma organização por vezes não é fácil, tendo em vista que as estruturas, regras e a falta de autonomia são alguns empecilhos encontrados nesta difícil empreitada. A criatividade, assim, resta empoderada por iniciativa do indivíduo inconformado com o modelo vigente.

A criatividade descreve a propensão pessoal para o desenvolvimento, criação e inovação em qualquer área do conhecimento. Araújo et al. (2017) destacam que a criatividade está intimamente ligada à ação empreendedora, uma vez que o ato de criar produz inovações em métodos, produtos e mercados. $\mathrm{O}$ experimento do novo, das novas formas, que faz com que surjam diversos meios, numa perspectiva gerencial, mesmo em espaços educacionais (MUZZIO, 2017) ou, para Dória et al. (2017, p. 291), criatividade e inovação têm estreira relação, servindo para romper "[...] com práticas anteriores para implantação de mudanças". Bessant e Tidd (2009) afirmam que a critividade fornece elementos que permitem pensar em incontáveis possibilidades, contribuindo para ampliar as oportunidades, facilitando a melhor alternativa.

A criatividade no meio organizacional vai além de desempenhar um trabalho criativo, mas "é essencialmente centrada em uma escolha individual entre a rotina e a novidade" (BESSANT; TIDD, 2009, p. 60), ou seja, tem-se por base a premissa de que uma pessoa pode desempenhar resultados satisfatórios e produtivos de forma diferente do que sempre se tem feito e tal situação está diretamente ligada à postura de assumir riscos independentemente da aprovação das estruturas. É, por assim dizer, 
adotar uma atitude inconformista e inovadora ou a partir de um movimento proativo de ideação, como aduzem Borchardt e Santos (2014, p. 205), para quem "corresponde à transformação da inteligência competitiva em ideias/insights que levem efetivamente ao aproveitamento das oportunidades identificadas".

Braum, do Carmo e Sá (2006) destacam que estudos concebidos pelos humanistas Rogers e Maslow demostram que condições ambientais facilitam o aparecimento da criatividade. "Nestes estudos, conceberam a criatividade como resultado de uma interação mutuamente benéfica entre o ser humano e o ambiente". (BRAUM; DO CARMO; SÁ, 2016, p. 3). Desse modo entende-se que a criatividade no âmbito organizacional sofre influencias de vários aspectos, visto que a criatividade organizacional é "um processo originário das características de personalidade, conhecimento, habilidades e motivação dos membros da organização" (BEDANI, 2012, apud ARAÚJO et al., 2017, p. 99). É preciso destacar que o ambiente organizacional em que o indivíduo se encontra tem um peso considerável no constructo empeendedor e isto pode estimular ou não o espírito empreendedor do gestor público (ARANA; SILVA, 2016).

\section{Gestão Pública}

A gestão pública é inerente à Administração Pública que, por sua vez, assume dois sentidos: na primeira divisão, encontram-se os conceitos ligados à Ciência Administrativa, a qual está atrelada à figura do governo e do executor. Complementarmente, os conceitos relacionados à Ciência Jurídica compreendem as atividades desenvolvidas pelos agentes públicos que visam ao atendimento das necessidades e bem comum (PALUDO, 2013). Ao longo da história do Brasil, a gestão pública assumiu diversos modelos de acordo com a época, o poderio que o administrava, assim como as exigências do momento e as necessidades da sociedade que o compunha/compõe. Três modelos de gestão já foram aplicadas historicamente à Administração Pública: gestão patrimonialista, gestão burocrática e o modelo gerencial. Estes modelos diferem um do outro e vão sendo implementados de acordo com as exigências que o progresso e a mudança de época exigem.

Secchi (2009) aponta que o marco que deu início ao novo modelo da gestão pública, deu-se com o lançamento do livro "Reinventando o governo" de Osborne e Gaebler, em 1992, o qual apresentou pela primeira vez o chamado governo empreendedor, um novo estilo de gerência pragmática da gestão pública utilizando fatores e instrumentos comuns à gestão privada na gestão pública. Identifica-se, portanto, que mesmo na esfera pública a necessidade de responder de maneira efetiva aos anseios do tecido societário torna-se iminente e urgente.

Desse modo, os órgãos ou agentes públicos são aqueles que, apoiados em recursos do Estado, mantém, dirigem e controlam, bem como buscam por meio de processos e modelos gerenciais atender às necessidades visando ao bem comum. Para o atendimento satisfatório de tais necessidades, é necessário o desenvolvimento de funções gerenciais que dão origem à gestão do meio público. Santos (2014, p. 47) conceitua gestão pública como "o planejamento, a organização, a direção e o controle dos bens e interesses públicos, agindo de acordo com os princípios administrativos, visando ao bem comum por meio de seus modelos delimitando tempo e espaço". Assim, o conceito estende-se para uma efetiva busca de resoluções de questões inerentes à gestão pública, tais como garantia de saúde e educação de qualidade, redução dos níveis de desigualdades sociais, expansão e preservação da cultura do seu povo e proteção dos recursos naturais de seu território (MATIAS-PEREIRA, 2009). Resta evidenciado que o conceito de gestão pública perpassa por ações efetivas e eficazes com vistas a atender, sob uma perspectiva integral, os anseios da sociedade. 


\section{Gestão no Espaço Educacional}

O termo gestão vem do latim gestio, que significa executar, obter sucesso, resultados de qualidade, através do planejamento. Para Cunha (2016, p. 34-35), a partir de Daft (2010), "a função da gestão é otimizar o funcionamento dos negócios ou das organizações através da resolução de tomar decisões que sejam racionais e fundamentadas na coleta de informações de relevância, e assim, contribuir para o seu desenvolvimento". Dentro das universidades, a gestão ocorre por meio de atividades e procedimentos administrativos de caráter acadêmico-pedagógico, que por muitas vezes são pautados em planejamentos deliberados em colegiados, com vistas a atingir o objetivo de maneira eficaz e eficiente. O gestor universitário, em geral, é docente portador do título de doutor, porém, para além de habilidades didáticas, os gestores-docentes precisam deter ou desenvolver habilidades gerenciais com fulcro em elementos da Administração Científica, em muitos aspectos.

Para o cumprimento de tais práticas, habilidades relacionais - como ser visionário, planejado, ser capaz de tomar decisões, possuir boa comunicação interpessoal, reunir aspectos de liderança, dominar a tecnologia e saber gerenciar informações - auxiliam o gestor nessa complexa tarefa de dirigir uma Instituição Federal de Ensino. Um fator que merece destaque e que facilita as gerências das IFE brasileiras é o fato de que, conforme preconizado no artigo 207 da Constituição Federal (CF), as Instituições possuem autonomia administrativa, didático-científica e de gestão financeira e patrimonial. Deste modo, a liberdade administrativa e financeira no uso dos recursos confere à gestão das IFE uma leveza no momento da tomada de decisão por parte do gestor, não estando, eventualmente, submetido ao controle, permitindo que o movimento de criação e inovação possa prevalecer sob uma concepção discricionária. Mas, não raro, os gestores se restringem às determinações legais e ao espaço de manobra pessoal, não admitindo caminhar para além do que é previsto nos Regimentos institucionais. De todo modo, empreender ações de caráter inovador e criativo nestes ambientes depende, em elevada medida, do comportamento do gestor público, com destaque àqueles que assumem o protagonisto das transformações necessárias ao pleno funcionamento da instituição que dirige.

\section{Procedimentos metodológicos}

Para atender ao objetivo do estudo, foi realizada uma pequisa descritiva-exploratória, de abordagem qualitativa, recorrendo-se ao Estudo de Caso como técnica de pesquisa (YIN, 2001). Os sujeitos da pesquisa foram os 3 (três) diretores das únicas Instituições Federais de Ensino da cidade de Floriano: Universidade Federal do Piauí - UFPI; CTF - Colégio Técnico de Floriano e Instituto Federal de Educação, Ciência e Tecnologia do Piauí - IFPI.

Para a realização da coleta de dados, por meio de entrevistas, foi elaborado um questionário semiestruturado composto de 7 questões, discutindo o comportamento dos gestores em IFE sob a perspectiva empreendedora. Para a análise e interpretação dos dados a pesquisa se apoiou na Análise de Conteúdo (BARDIN, 2011), cujo foco é analisar o conteúdo da mensagem, extraindo as informações considerando não só apenas a literalidade do depoimento, mas, sobretudo, buscando promover a interpretação das entrelinhas nas falas, levando em conta as respostas e o cenário de fundo que as influenciaram. As entrevistas, todas gravadas para posterior transcrição, foram realizadas entre os dias 26/04/18 e 07/05/18 e ocorreram nos campi das instituições. Visando a manter o sigilo das informações e dos sujeitos da pesquisa, foi definido que os entrevistados foram identificados pelos códigos E1, E2 e E3.

Em respeito aos aspectos éticos que envolvem as pesquisas com pessoas e para atender à necessária 
imparcialidade em estudos desta natureza, os pesquisadores não manifestaram qualquer sentimento de concordância ou discordância diante das respostas colhidas ou expuseram conduta que pudesse indicar um desejo ou uma tendência. Antes de iniciar a etapa da coleta dos dados, foi apresentado aos sujeitos da pesquisa o TCLE - Termo de Consentimento Livre e Esclarecido, oportunidade em que foram apresentados os propósitos, o problema e o alcance do presente estudo. Objetivando a análise dos resultados, foi adotado primeiramente uma préanálise, na qual foi promovida a organização e a transcrição do material obtido, bem como a leitura de todos os recursos teóricos da pesquisa, estabelecendo e verificando a relação entre os objetivos propostos e as respostas dos entrevistados.

Logo em seguida, encaminhou-se para a análise oral das entrevistas propriamente ditas, a fim de detectar a relação existente entre a teoria e os discursos colhidos em cada diálogo. No próximo tópico são apresentados os depoimentos, cujas falas buscam retratar a realidade da gestão pública em IFE, tendo como pano de fundo as possibilidades de criação, inovação e ideação na condução das instituições por parte dos gestores entrevistados, sempre lembrando que se tratam de gestores que conduzem organizações educacionais públicas, regidas por dispositivos legais ancorados nos Príncípios que norteiam a Administração Pública e o Direito Público.

\section{Apresentação e análise dos resultados}

Para conceber consistência ao estudo, todas as respostas foram transcritas ipsis litteris. A pergunta 01 [A estrutura organizacional da sua instituição desencoraja o intraempreendedorismo?] teve o seguinte posicionamento:

E1: Desestimula, desestimula porque o orçamento é centralizado, o empreendedorismo, é o empreendedorismo que você perguntou né? [sic] $\mathrm{O}$ empreendedorismo dentro do setor público é diferente do setor privado, o meu papel aqui como gestor é pensar na melhoria do campus, se eu tenho o orçamento e tenho um conselho pra decidir quais serão os melhores investimentos, não só a nível é de capital, de custeio, mas a nível também de agregar novos valores, agregar novos cursos eu passo a poder pesar melhor sobre o que fazer né empreender no campus como tudo é centralizado a gente deixa a desejar, nós podíamos ter resultados muito melhores se não fosse centralizado, então hoje para nós pensamos em uma melhoria e temos que disputar o orçamento, disputar o investimento, vender a ideia junto à gestão superior e com isso nós estamos disputando com todos os outros campi, mais a sede, em Teresina.

E2: No ambiente de gestão, que é o foco da sua pesquisa, eu visualizo o empreendedorismo como ação é em que o gestor ele não fica sentado aqui nessa cadeira da direção esperando que as coisas aconteçam, pra gente resolver um problema a nível institucional não adianta ficar aqui fazendo ligações ou tentando resolver pelo WhatsApp, por e-mail ou pelo próprio sistema acadêmico da Instituição a gente precisa correr pras reuniões em Teresina, buscar parcerias com Instituições públicas aqui da cidade pra poder resolver os nossos problemas né que não são poucos, então dentro da instituição nós temos essa abertura pra que cada servidor, ele tome a sua frente com relação a isto não vai ser o diretor que vai tá [sic] dizendo pra servidor $\mathrm{A}$ ou $\mathrm{B}$ que ele deveria tá fazendo determinada atividade pra melhorar o próprio ambiente de trabalho, cada servidor tem essa autonomia de fazer isso, então quando eles vêm aqui pras reuniões e colocam as demandas a gente percebe que há um interesse em que aja uma melhora no ambiente de trabalho e a instituição ela procura garantir dentro da lei tudo aquilo que for possível pra fazer esse projeto ir pra frente.

E3: Assim, a gente tem hoje as coordenações com muita independência né [sic] pra 
desenvolver os seus projetos, a gestão do campus ela sempre procura apoiar as iniciativas dos setores, sobretudo dos cursos né [sic], aqui das coordenações de curso, então eu acredito que a gente encoraja, que a gente dá essa abertura para os coordenadores, para os chefes de setores inovarem nos seus setores.

Analisando o questionamento anterior, vê-se que os resultados apontam para uma gestão pública centralizadora e controladora orçamentariamente falando, em que a estrutura desestimula o intraempreendedorismo. No entanto, os entrevistados enxergam na própria gestão uma maneira de estimular os servidores/colaboradores a terem iniciativa no momento em que conferem a eles a autonomia no desempenho das tarefas. A autonomia é um aspecto importante quando se fala em empreender/intraempreender. Hashimoto (2006) afirma que a autonomia permite que o indivíduo intra/empreendedor define, dentre outras coisas, o uso de estratégia para ações e para a busca de oportunidades relevantes no curso da ação delegada.

A pergunta [Em sua opinião, é possível a gestão de uma Instituição Federal ser criativa? Poderia nos dizer como?] foi assim respondida pelos entrevistados:

E1: Nós aqui, é o que eu estou dizendo, nós não temos recursos, os recursos são todos centralizados, no entanto nós fazemos o campus avançar um exemplo aí o laboratório de Administração, o laboratório de Administração foi uma concepção do professor [docente que realizou o projeto], o laboratório de produção foi uma concepção do professor [docente que realizou o projeto], nós tivemos que vender a ideia a gestão superior comprar a ideia, o Pró-Reitor de Planejamento fazer a rubrica, os recursos virem de Brasília e a gente coloca o campus, foi uma ação empreendedora que vai gerar frutos. O laboratório de Enfermagem foi o primeiro laboratório de Enfermagem de todos os cursos da [instituição à qual está ligado o campus] a ter um simulador, um boneco simulador de doenças, foi o primeiro a ter, foi uma..., foi a [docente que realizou o projeto] que fez a proposta, nós vendemos a ideia, então quer dizer foi uma ação empreendedora de sucesso. Essa semana a Pró-Reitora de Extensão esteve aqui e ficou encantada com a brinquedoteca que é um laboratório de Pedagogia, a brinquedoteca em outros campi estão fechadas há muitos anos, então foi fruto do trabalho dos professores daqui, também uma ação empreendedora, apesar dos recursos serem centralizados é lidar com criatividade e com coesão do corpo de gestores, de docentes e discentes principalmente, faz com que o nosso campus avance.

E2: É, bom cada gestor ele possui uma filosofia de trabalho, os outros diretores que me antecederam possui a filosofia deles de trabalho e quando nós assumimos a gestão nós procuramos implantar, os métodos de trabalho que a gente acreditava que poderiam modificar a nossa instituição, modificar no sentindo de melhorias, né, algumas não bem vistas pelos servidores, outras já aceitas, mas, enfim a você receber a instituição e dá continuidade ao trabalho a que estava sendo executado pra mim gera o aspecto negativo justamente porque a quando nós temos um novo gestor à frente da instituição toda comunidade ela espera que haja mudanças né, [sic] no sentido de melhoria da própria instituição então eu acredito que essa expressão “criatividade" ela tá diretamente ligada às ações que são executadas durante todo o processo de gestão.

E3: Sim, é possível, apesar das dificuldades, apesar da burocracia, apesar da necessidade de recursos como eu falei agora há pouco, o orçamento, nós não geramos orçamento, nós dependemos diretamente do orçamento federal, mas é possível sim criatividade e eu vou dá um exemplo do que nós fizemos aqui o campus: nós temos um restaurante institucional e o nosso restaurante ele até 2015, é funcionava com a compra dos tickets, tickets em papel onde o aluno ia lá e comprava 
e utilizava no restaurante, é não só aluno, é aluno e servidor, e aí de 2015 prá [sic] cá nós temos usado um sistema de informação que é o chamado SARI (Sistema de Acesso ao Restaurante Institucional) onde é a gente eliminou todo o processo de papel, todo o processo que era impressão, corte e distribuição e vendas dos tickets foi eliminado, inclusive a partir daí nós tornamos o acesso gratuito ao restaurante institucional e hoje os alunos eles reservam o seu ticket através de um sistema, onde é o acesso dele no restaurante no acesso físico se dá por meio da apresentação da carteirinha e pela leitura do código de barras, o aluno ele entra no sistema, ele acessa o sistema, ele reserva o seu ticket e ele acessa mediante a apresentação da carteirinha, isso é uma inovação que foi feita nessa gestão é e aí nesse mesmo sistema os servidores, eles utilizam também o sistema só que eles geram uma GRU, uma Guia de Recolhimento da União, fazem o pagamento do seu, da sua GRU e utilizam no restaurante né, também mediante sistema, mediante o mesmo processo, ele acessa o sistema reserva e acessa ao restaurante por meio do seu crachá, da sua identidade funcional. Uma outra inovação que eu poderia citar, que foi o nosso sistema de energia renováveis, né [sic] de energia fotovoltaica, que foi o primeiro sistema de minigeração do Estado do Piauí e foi numa Instituição Pública Federal de Ensino, aqui no [lócus de atuação do gestor], onde nós por meio de apoio da reitoria, óbvio, nós investimos um 1,5 milhão reais e montamos um sistema onde hoje $40 \%$ da energia consumida o campus é energia gerada de uma fonte renovável, no caso o sol, paralelamente a isso é e como consequência disso a economia gerada no primeiro ano de funcionamento do sistema, nós fizemos a troca de todas as lâmpadas é internas do campus por tecnologia LED, o que nos tem gerado também economia de energia e hoje nós estamos experimentalmente montando um sistema onde nós reaproveitamos a água liberada dos ar condicionados na exaustão, então essa água que é liberada do ar condicionado ela vai para um recipiente para uma caixa d'água e por meio de um bombeamento, movido a energia solar também, essa água ela é utilizada para a irrigação dos jardins do campus, esse projeto já tem uma parte que já está em execução e faz parte da agenda ambiental da Administração Pública, a 3P. Outro exemplo aqui no campus dessa mesma linha ambiental, nós não compramos mais copos descartáveis, todos os servidores receberam uma squeezer onde a gente não mais compra copos descartáveis, foi uma outra ação importante nesse mesmo sentindo nessa mesma direção e recentemente nós instalamos aqui a nossa academia institucional, onde os nossos servidores e os nossos alunos atletas eles já estão tendo acesso e aí também eu acredito que seja uma inovação, para os alunos que participam de torneios eles têm uma preparação física melhor e para o servidor ele cuida da saúde pra prestar um serviço melhor pra sociedade, então acredito que também seja um exemplo de inovação, outro exemplo que eu poderia dar é que quando é, um problema que a gente tinha aqui de comunicação e hoje a gente tem TV `s espalhadas no campus, são três TV's, onde a gente coloca banners essas TV's para divulgar informações, então logo aqui na entrada do campus tem uma TV, então toda a informação nova a gente faz um banner no setor de comunicação e publica lá na TV, então automaticamente alunos e servidores têm acesso a essa informação de forma rápida né [sic], foi também uma outra informação e tudo isso mediante uso da tecnologia.

A criatividade é um motor que faz com que se encontrem soluções diante de situações que muitas vezes fogem ao controle. Na gestão pública, submetida a rígido controle, descobrir e implementar soluções criativas faz toda a diferença. Conforme Bessant e Tidd (2009), ser criativo no ambiente organizacional consigna uma escolha entre a rotina e a novidade, ou seja, é preciso pautar as decisões e manter um equilíbrio entre buscar algo novo e manter velhos hábitos. $\mathrm{Na}$ fala dos gestores, observase que apesar do rigoroso controle, buscar e implementar soluções criativas além de possíveis, conferem também uma dinamicidade e flexibilidade à gestão, configurando uma proximidade com o 
modelo gerencial. Uma das características que expressam isto é a adoção de uma postura de governo preventivo, em que, segundo Osborne e Gaebler (1992) apud Secchi (2009), os gestores abandonam posturas reativas na solução de problemas e implementam uma postura ativa por meio do planejamento, executando ações independentemente de pressões externas.

A indagação [O senhor acredita que no âmbito educacional, subordinado às determinações legais pelo caráter público, há espaço para inovações?] pretendeu descobrir se é possível inovar em ambiente burocratizados. As respostas foram as seguintes:

E1: Existe, existe espaço para inovar porque não é... como é que eu vou dizer, o ensino ele não está limitado por ações, as ações são amplas então, cabe ao professor estabelecer as inovações, todo professor tem liberdade para estabelecer inovação, a disciplina é, ele é o gestor da disciplina ninguém pode interferir na disciplina, nem o diretor, nem o chefe de curso, nem o reitor, só quem é o gestor da disciplina é o professor, a partir do momento que ele está vinculado a disciplina, então ele pode inovar, ele pode inovar com, com aquilo que a lei permite se o ensino é presencial obviamente que ele não pode inovar fazendo com que a disciplina seja feita por um ensino a distância, mas ele pode inovar utilizando o próprio [sistema de gestão acadêmica da instituição], não é que é uma inovação no ensino que nós temos disponível na , [instituição à qual está ligado o campus] pra que ele utilize na.. em discussões on lines, em banco de materiais, respostas a distância sem, contudo, descaracterizar um curso que é presencial, é possível inovar mesmo com as limitações que a lei estabelece, a lei é lei ampla ela não é tão limitadora assim que impede que você avance ou faça coisas novas, não, não é se alguém não faz é porque não quer, professor ele tem liberdade pra fazer trabalho de campo, professor tem liberdade pra fazer visita técnica, então quer dizer isso é inovar, o professor da disciplina A e o professor da disciplina B ministram a disciplina de forma diferente e se mudar o professor pode acontecer também, então quer dizer é possível inovar.

E2: Há espaço sim, constantemente e nós desenvolvemos atividades que devem estar baseadas em alguma legalidade, nós não podemos tá [sic] executando nenhuma ação aqui que fuja à legalidade, mas quando a gente fala em projetos é de pesquisa e extensão a gente percebe que os alunos eles buscam executar ações que às vezes não têm respaldo, então a gente precisa de autorizações, o próprio Comitê de Ética ele é uma coisa nova é então no passado não existia esse tipo de preocupação que vocês estão tendo agora no momento por exemplo com o Comitê de Ética, então as pessoas faziam pesquisas inclusive com humanos né de forma bastante livre e isso não pode né então a base legal ela deve acontecer nós entendemos que apesar de existirem tentativas de fugir a isto é nós entendemos que toda ação as instituições públicas deve ser regida por uma base legal, caso isso venha querer a sair dessa linha essa ação deve ser imediatamente suspensa, visto que nós temos riscos que podem vim a acontecer e quem vai responder isso é o gestor, então eu discordo com ações que é não tenham base legal.

E3: Sim, como eu já acabei de dá vários exemplos.

A inovação das IFE na fala dos gestores ocorre prioritariamente na sala de aula com os docentes. Suas gestões se mostram abertas e conferem aos demais profissionais autonomia e liberdade para atuarem. Hashimoto (2006) chama a atenção para o fato de que a inovação abrange a criação de novos métodos de produção e promove mudanças estruturais na organização. Foi verificado também que existe uma preocupação por parte dos gestores para as inovações não irem contra a lei, por outro lado, eles entendem que a lei não é uma limitação para inovar. Ou seja, mesmo no espaço público, medidas inovadoras e criativas podem ser aplicadas sem ferimento aos dispositivos legais que restrigem a atuação do servidor público. As questões [O senhor desenvolve sua gestão como um empreendedor?] 
e [O senhor se considera um intraempreendedor?] buscaram desvelar se o gestor se considera um indivíduo que empreende, mesmo em ambientes supostamente estáticos, configurados com a rigidez das normas institucionais. Assim responderam os pesquisados:

E1: Não, eu consigo sim, eu desenvolvo a gestão da seguinte forma de maneira descentralizada, cada gestor aqui no [lócus de atuação do gestor] é responsável pelo seu setor e cabe a eles a execução, o meu papel aqui como gestor é pensar a melhoria defender o campus nos conselhos superiores e fazer com que a gente avance, avance como? Exatamente inovando, avance exatamente propondo ideias novas que possam fazer com que o campus se modifique e revolucione a forma de pensar, revolucione na forma de nós ensinarmos, então quer dizer se você comparar esse campus aqui com os outros da [instituição à qual está ligada o campus] nós somos o único campus que temos um laboratório de informática liberado pros [sic] alunos e um outro fechado só pra sala de aula, é o único campus que tem isso, a primeira biblioteca a permitir que os alunos acessassem os livros foi aqui, as outras bibliotecas não podiam pegar o livro, o aluno tinha que pegar pelo computador entregar uma fichinha que pra bibliotecária ou pra quem fosse do serviço e lá entregar o livro pro aluno, a nossa bibliotecária veio, conversou com o diretor, conversou comigo né e falou professor eu entendo que o livro o aluno deve ter acesso, porque é igual a um mercado, ele olha para um produto e leva o outro porque vê que é bom, então o aluno precisa ir até o livro ele precisa ir até a estante. Qual foi o meu papel? Buscar a forma para que isso fosse executado, então nós fomos o primeiro a ter aquele portal de fitas magnéticas que foram coladas nos livros, então, quer dizer, eu entendo que a gestão empreendedora é essa é buscar inovar, buscar avançar e pensar melhoria, meu papel é fazer a gestão.

E2: Acredito que na segunda pergunta isso já foi contemplado, é porque como eu já disse a palavra empreendedorismo o meu sentido já que sou formado em Administração de Empresas também ele tá diretamente ligado à questão de o indivíduo ele sair da zona de conforto e buscar mecanismos pra poder vencer né [sic], então eu vejo o empreendedorismo como uma flecha nessa direção, porque se você ficar estagnado você não vai conseguir resolver os problemas, então como eu já disse anteriormente, se nós ficarmos aqui estagnados esperando que as coisas aconteçam a escola não vai andar, então eu me considero um empreendedor nesse aspecto justamente porque se for pra eu resolver um problema e tiver que ir lá em Brasília amanhã eu já tô [sic] arrumando minha bagagem, então é isso pra mim está diretamente ligado ao empreendedorismo.

E3: Eu acredito que é utilizando criatividade, pensando e procurando as melhores soluções, não sei se exatamente como um empreendedor, mas é procuro sempre buscar soluções criativas né [sic] pra que a gente possa é avançar na gestão do campus.

É possível visualizar que parte dos entrevistados desenvolve sua gestão de forma empreendedora, ao buscar alternativas, conseguir ser dinâmico, descentralizador e conferir autonomia aos seus liderados. Estes traços denotam e apontam para uma gestão intraempreendedora. Ao desenvolverem suas gestões de maneira empreendedora, pode-se destacar o modelo McMullen-Shepherd, em que o conhecimento e a motivação impactam diretamente na ação empreendedora que, no caso dos gestores sob investigação, seu conhecimento prévio influencia na motivação para tomar as decisões, sempre tendo em vista o avanço na gestão. Prosseguindo nas arguições, os gestores se posicionaram da seguinte forma em relação à pergunta [O senhor se considera um intraempreendedor?]:

E1: Sim, até porque as coisas aqui não são decididas pelo diretor, são decidas pelo um corpo de gestores, não é, então eu considero que sim, tudo o que nós 
avançamos aqui não foi ideia do diretor, foi o diretor esteve aberto a receber ideia e buscar os recursos para que elas fossem executadas, algumas foi o próprio diretor que pensou e buscou apoio dos gestores para que nós pudéssemos implementar, então eu compreendo que sim.

E2: Eu acredito que sim, porque apesar de eu ser gestor eu nunca saí das minhas atividades em sala de aula, eu nunca abandonei pesquisa nem extensão, participo de todas as reuniões de curso da instituição motivando os servidores a buscarem atividades que melhorem o desempenho institucional e estou sempre envolvido diretamente em todas as ações da [lócus de atuação do gestor], não há nada dentro desta da [lócus de atuação do gestor] que aconteça sem passar por mim, não no sentido de que eu sou o representante máximo da instituição, justamente porque essa decisão ela tem que ser conjunta e eu preciso orientar todos os servidores sobre as ações que são tomadas justamente pra que a coisa funcione de maneira melhor, porque eu tenho a visão do todo.

E3: Acredito que de certa forma sim, alguns desses projetos que eu citei agora há pouco são projetos que tiveram riscos e a gente junto com a equipe, claro, e analisando os riscos, têm executado.

Os gestores responderam de forma positiva ao questionamento de se considerarem intraempreendedores. São várias as questões que se encontram ao redor do intraempreendedor. O intraempreendedor é aquele que mesmo estando em uma estrutura que não foi criada por ele, consegue gerir de modo autônomo buscando soluções. São indivíduos que operam meios para entregar o melhor às pessoas que servem. Como servidores públicos que são, desenvolvem mecanismos, não obstante o caráter limitador das ações, visando à prestação de serviço mais justa e eficaz. Wunderer (2001) aponta que o intraempreendedor é aquele que além de inovar, cria oportunidades e descobre novos recursos para agregar valor. A dinamicidade em realizar tarefas, além de gerir a postura de tomar decisões em conjunto, levando em consideração as opiniões de outros colaboradores e a atitude de correr riscos, são questões que apontam para um perfil intraempreendedor nos gestores. Ao serem questionados $[\mathrm{O}$ excesso de burocracia afeta o seu desempenho empreendedor? Como?], assim responderam os participantes:

E1: A própria centralização, e têm outros aspectos que dizem respeito por exemplo a órgãos externos a [instituição à qual está ligado o campus] nós também não podemos é aqui responsabilizar só a [instituição à qual está ligado o campus] é os órgãos de controle igual a CGU eles exigem que determinadas ações só possam ocorrer através de processos, então o processo que tem que ser montado em Floriano a $240 \mathrm{~km}$ da sede ir até Teresina por malote e ter que retornar pra [sic] cá obviamente que é uma burocracia cumprindo por causa da CGU então essa daí eu não responsabilizo a [instituição à qual está ligado o campus], mas por outro lado, por exemplo, um diploma que vem pra cá pra o aluno assinar, depois volta Pró-Reitor assinar prá depois voltar pra [sic] cá pra entregar pro aluno já é uma falha da gestão [instituição à qual está ligado o campus] e é uma falha que nós gestores de campus não temos como fazer nada porque é uma decisão superior, a gente já opinou, já opiamos, já dissemos que tem que melhorar, mas não conseguimos avançar, o reitor prometeu por exemplo que os diplomas vão ser entregues no dia da formatura porque vai ser on line e ele vai entregar, ótimo é tudo o que nós desejamos, então quer dizer é uma burocracia que atrasa, nos atrasa como servidores, atrasa o discente que acabou de colar grau, precisa do diploma e não tá lá, então quer dizer é uma burocracia que precisa ser superada ainda mais nos dias de hoje.

E2: Demais, totalmente um dos elementos mais nocivos na instituição pública chama-se a bu-ro-cra-cia, por exemplo nós temos obras que estão sendo 
realizadas e após dois anos de solicitação, nós temos um documento que vai auxiliar em diversos aspectos a nossa instituição e ele está sendo analisado há um ano, e hoje, no momento, nós estamos com o transporte da instituição parado, então diversos programas ou atividades que aconteceriam foram suspensos porque a burocracia ainda não resolveu o problema do seguro dos veículos, então com isso pára tudo, vamos realizar um evento cientifico em Fortaleza, suspenso! Vamos para a viagem técnica em São Raimundo Nonato, suspenso! Justamente por conta dessas questões burocráticas.

E3: Certamente, nós temos é, o campus ele é muito arborizado e nós precisávamos adquirir um equipamento que é caro, precisamos na verdade, adquirir um equipamento que é caro, pra dar mais segurança e facilitar o trabalho, em relação à manutenção das nossas árvores e também pra outros trabalhos e infelizmente a gente não pôde ainda adquirir esse equipamento por ser um equipamento um pouco caro e aí a burocracia e a falta de recursos têm impedido isso.

A burocracia é um modelo utilizado como resposta para gerir, sendo pautado no formalismo, na impessoalidade e no profissionalismo, tendo sua força e poder decorrentes das normas, o que em tempos passados constituía-se como uma resposta eficiente. Mas, com o progresso e o imediatismo causados pela globalização, o modelo burocrático passou a não mais responder de forma satisfatória. A burocracia passa a ser então algo impeditivo - embora exigível, como observado nas falas dos entrevistados: atividades param unicamente por conta da burocracia, no momento em que concentram as atividades em apenas uma pessoa e limita os recursos, ficando o atendimento ao público prejudicado. Em IFE, o modelo burocrático é necessário, face à complexidade dos processos e dos sistemas que as constituem. Todavia, percebe-se, nos depoimentos, que falta dinamismo e avanços quanto à desburocratização de algumas etapas, cujo produto final poderia proporcionar eficiência na tomada de decisão, agilidade na entrega dos serviços educacionais e economia financeira para os cofres públicos.

Por fim, a pesquisa procurou descobrir como os gestores buscam alternativas para atender às demandas do seu público (servidores, técnicos administrativos, docentes e discentes), com a questão [O senhor costuma buscar alternativas para atender às demandas gastando menos?], tendo os entrevistados assim se posicionado:

E1: Sim, vou te dar um exemplo: aqui foi solicitado a construção de uma casa de vegetação no campus, essa casa de vegetação os professores pediram e a casa custava 60 mil reais, nossa casa de vegetação ficou em 8 mil reais, então quer dizer nós buscamos uma alternativa pra atender o que o professor queria, estar dentro das normas técnicas, mas de forma bem mais barata e nós conseguimos. Por exemplo, a doação de madeira do IBAMA apreendida de maneira ilegal, então essa madeira é utilizada pelo campus, nós que buscamos o IBAMA, ó [sic] nós precisamos de madeira, então a gente busca as parcerias com os órgãos governamentais pra poder avançar, então é exatamente a criatividade que permite com que o campus está do jeito que está, principalmente o comprometimento de gestores, docentes e discentes em querer manter o campus.

E2: Sim, porque como nós sabemos que os recursos são limitados nós não podemos tomar decisões que comprometam o andamento da instituição até o fim do ano, é o ano letivo, nós não podemos, então se nós entendermos que algo pode vir a prejudicar financeiramente a instituição essa solicitação será indeferida independente do impacto que isso pode causar a quem solicitou.

E3: Sim, claro, como citei, o próprio sistema que foi criado lá do refeitório foi 
um sistema que foi é desenvolvido pelo nosso analista de sistemas e teve custo, fora o trabalho do analista, custo zero pra instituição, o sistema tá hospedado aqui no nosso servidor e a gente eliminou com isso todo o gasto de papel que tinha diariamente, como também de um servidor pra operar isso aí, pra fazer a logística, com pouco recurso, assim como a troca das lâmpadas, o reuso da água, então uma série de empreendimentos que são feitos nesse sentido, buscando melhorias.

Ao analisar as falas, um fator interessante que merece destaque é a postura proativa dos gestores, a busca de alternativas para atender às demandas por parte dos gestores, o que evidencia uma preocupação com a satisfação dos clientes da IFE, seja porque estes devem ter suas necessidades atendidas, seja pelo fato de serem agentes e protagonistas dessa gestão no momento em que suas opiniões são levadas em consideração e no momento em que é cultivado neles o sentimento de pertencimento, porquanto dão subsistência ao Serviço Público na condição de contribuintes.

Neste ponto, os gestores, além de adotarem postura intraempreendedora, incorporam também uma conduta do modelo gerencial, em que a estratégia construtiva é decidida por meio da participação dos envolvidos. Como intraempreendedores, os gestores não se amedrontam com os problemas, pelo contrário, são motivados pela resolução destes e pela inovação implementada para resolvê-los (LUCHSINGER; BAGBY, 1987), enfrentando com vigor, determinação e visão diferenciada os dilemas que naturalmente existem no ambiente acadêmico.

As falas permitem concluir que apesar dos traços empreendedores serem mais prevalentes e notáveis em alguns, o intraempreendedorismo pode ser desenvolvido em todos os indivíduos, independentemente de fatores como formação acadêmica ou titulação, por exemplo. O fato é que para ser intraempreendedor, torna-se vital o sujeito compreender que o seu comportamento ditará as regras da iniciativa inovadora e criativa.

\section{Considerações finais}

Este estudo visou a descrever as possibilidades de ser criativo e empreendedor atuando na gestão pública de uma IFE. Constatou-se que os gestores têm um perfil empreendedor semelhante ao empreendedor por necessidade e ao empreendedor por inovação, ou seja, ao receberem uma demanda, eles buscam alternativas para executá-la com os recursos que dispõem. Em outros momentos, ao perceberem um problema, criam e buscam soluções não exploradas anteriormente para também sanar a deficiência. Em qualquer das vertentes, agem e não hesitam em viabilizar instrumentos com vistas a defender os interesses dos stakeholders, priorizando, como se pôde observar, as demandas dos usuários primários.

No tocante aos obstáculos que impedem a presença do empreendedorismo no Serviço Público, restou evidenciado que os dois obstáculos são a burocracia e os limites orçamentários, pontuando-se que propor novos projetos nesse regime requer discernimento e persistência, fatores primordiais na seara empreendedora. As falas também revelaram quais medidas poderiam ser implementadas para caracterizar um comportamento empreendedor, sendo constatado, a partir da análise das ações dos gestores, a preocupação com o meio ambiente, a gestão participativa, o desenvolvimento do sentimento de pertencimento que eles estimulam na comunidade acadêmica das instituições sob sua gestão, a versatilidade no momento de executar as atividades e as soluções pautadas na tecnologia. Estes foram elementos observados e empregados para classificar o comportamento empreendedor dos gestores.

Esta pesquisa possui limitações, razão pela qual recomenda-se que novos estudos sejam promovidos 
com o fito de aprofundar o conhecimento acerca do processo inovador na ação gerencial em instituições educacionais. Muito possivelmente novas lentes serão desveladas com o entendimento dos gestores sobre a maneira como desenvolvem as suas habilidades e conhecimentos na condução de uma IFE. Com efeito, entende-se que o número de instituições poderá ser ampliado de maneira a dar maior substência ao fenômeno estudado. Adicionalmente, dependendo do tamanho da instituição, gestores de diversos segmentos podem participar de futuras pesquisas com o objetivo de abranger outras perspectivas no tocante ao tema ora estudado. Esta diversidade de falas e enredos pode contribuir para uma compreensão fidedigna e eclética, capaz de revelar as motivações e subjetividades envolvidas na gestão de instituições públicas.

\section{Referências}

ARANA, A. R. A.; SILVA, M. A. Empreender: Um Novo Olhar Sobre a Gestão Pública Brasileira. Revista Gestão. Org, v. 14, n. 1, p. 146-157, 2016.

ARAÚJO, C. C. S.; MODOLO, D.; CARNEIRO JÚNIOR, E.; VILS, L. Análise da relação entre clima organizacional e o desempenho criativo em organizações brasileiras. Navus-Revista de Gestão e Tecnologia, v. 7, n. 2, p. 97-112, 2017.

BARDIN, L. Análise de conteúdo. São Paulo: Edições 70, 2011.

BESSANT, J.; TIDD, J. Inovação e Empreendedorismo. Porto Alegre: Bookman, 2009.

BORCHARDT, P.; SANTOS, G. V. Gestão de ideias para inovação: transformando a criatividade em soluções práticas. INMR - Innovation \& Management Review, v. 11, n. 1, p. 203-237, 2014.

BRAUM, L. M.; DO CARMO, H. M. O.; SÁ, E. V. Criatividade no ensino superior: uma análise da percepção dos discentes sobre as práticas dos docentes. Revista Capital Científico-Eletrônica, v. 14, n. 4, p. 60-74, 2016.

CUNHA, K. S. Gestão universitária: significado para enfermeiros docentes do curso de graduação em Enfermagem de uma universidade pública. 2013. 127 f. Dissertação (Mestrado). Programa de Pós-Graduação em Enfermagem. Departamento de Enfermagem. Universidade Federal de Santa Catarina, Florianópolis, 2016.

DALARI, D. A. Elementos de teoria geral do Estado. Saraiva. São Paulo, 2012.

DÓRIA, A. S.; SANO, H.; LIMA, J. P.; SILVA, A. F. S. B. S. Inovação no setor público: uma instituição pública de ensino sob a ótica dos servidores e colaboradores. Revista do Serviço Público, v. 68, n. 2, p. 285-318, 2017.

DORNELAS, J. C. A. Empreendedorismo: transformando ideias em negócios. Rio de Janeiro: Campus, 2008.

HASHIMOTO, M. Espírito empreendedor nas organizações: aumentando a competitividade através do intraempreendedorismo. São Paulo: Saraiva, 2006.

HISRICH, R. D.; PETERS, M. \& Shepherd, D. A. Emprendedorismo. Porto Alegre: AMGH, 2014.

LUCHSINGER, V.; BAGBY, R. Entrepreneurship and intrapreneurship: behaviors, comparisons, and 
contrasts. S.A.M. Advanced Management Journal, v. 52, n. 3, p. 10-13, 1987.

MATIAS-PEREIRA, J. Manual de gestão pública contemporânea. São Paulo: Atlas, 2009.

MCMULLEN, J. S.; SHEPHERD, D. A. Entrepreneurial action and the role of uncertainty in the theory of the entrepreneur. Academy of Management Review, v. 31, n. 1, p. 132-152, 2006.

MUZZIO, H. Indivíduo, Liderança e Cultura: Evidências de uma Gestão da Criatividade. RACRevista de Administração Contemporânea, v. 21, n. 1, p. 108-124, 2017.

PALUDO, A. Administração pública. 3. ed. Rio de Janeiro: Elsevier, 2013.

PEREIRA, A. L. C.; SILVA, A. B. As Competências Gerenciais em Instituições Federais de Educação Superior. Cadernos EBAPE, v. 9, número especial 1, p. 627-647, 2011.

SANTOS, C. S. Introdução à Gestão Pública. São Paulo: Saraiva, 2014.

SARKAR, S. O empreendedor inovador: faça diferente e conquiste seu espaço no mercado. Rio Janeiro: Elsevier, 2008.

SECCHI, L. Modelos organizacionais e reformas da administração pública. RAP - Revista de Administração Pública, v. 43, n. 2, p. 347-349, 2009.

WUNDERER, R. Employees as "co-intrapreneurs": a transformation concept. Leadership \& Organization Development Journal, v. 22, n. 5/6, p. 193-211, 2001.

YIN, R. K. Estudo de caso: planejamento e métodos. 2. ed. Porto Alegre: Bookman, 2001.

ZAHRA, S. A. Goverance, ownershSip, and corporate entrepreneurship: the moderating impact of industry technological opportunities, Academy of Management Journal, v. 39, n. 6, p. 1713-1735, 1996. 